\title{
Direct Pharmacological Correction of Oxidative Stress in Rat Kidneys Does Not Facilitate Diabetic Nephropathy
}

\author{
A. Yu. Zharikov ${ }^{1,2}, \mathrm{PhD}, \mathrm{ScD}$; S.O. Filinova ${ }^{1 *}$; O. N. Mazko ${ }^{1}, \mathrm{PhD}$; \\ O. G. Makarova ${ }^{1}, \mathrm{PhD}$; I. P. Bobrov ${ }^{1}, \mathrm{PhD}, \mathrm{ScD}$ \\ ${ }^{1}$ Altai State Medical University, Barnaul, the Russian Federation \\ ${ }^{2}$ Scientific-Research Institute of Physiology and Basic Medicine, Novosibirsk, the Russian Federation
}

\begin{abstract}
The aim of this study was to evaluate the effect of alpha-tocopherol acetate (ATA) on the activity of free-radical oxidation (FRO) in renal tissue and renal function in rats with experimental streptozotocin (STZ)-induced diabetes mellitus (DM).

Methods and Results: Experiments were conducted on 22 male Wistar rats aged 60-100 days and weighing 250-300 g. The animals were divided into two groups: Group 1 (control) and Group 2 (experimental). To induce DM, the animals were injected intraperitoneally $1 \mathrm{ml}$ of STZ solution in the citrate buffer at a dose of $65 \mathrm{mg} / \mathrm{kg}$. For more selective modeling of type $2 \mathrm{DM}$, the rats were previously injected with an intraperitoneal solution of cytoflavin based on a nicotinamide dose of $115 \mathrm{mg} / \mathrm{kg}$. In Croup 2, ATA was administered in the period from the fifth to eighth weeks, inclusive, intragastrically through a tube at a daily dose of $300 \mathrm{mg} / \mathrm{kg}$.

Experiments showed that after a 4-week course of ATA, the concentration of thiobarbiturate-reactive products in the kidney tissues of the rats in Group 2 was 5.3 times lower than in Group 1. The activity of all antioxidant enzymes did not differ between the two groups. In both groups, during all 8 weeks of the experiment, the levels of renal excretion of glucose, protein, and creatinine significantly exceeded the initial level, while the level of diuresis remained stable.

Conclusion: The long-term administration of ATA in experimental streptozotocin (STZ)-induced DM is accompanied by a significant suppression of the activity of the FRO processes in the kidneys, but does not lead to an improvement in the course of diabetic nephropathy. (International Journal of Biomedicine. 2021;11(3):296-300.)
\end{abstract}

Key Words: kidneys $\bullet$ diabetic nephropathy $\bullet$ tocopherol acetate $\bullet$ oxidative stress

For citation: Zharikov AYu, Filinova SO, Mazko ON, Makarova OG, Bobrov IP. Direct Pharmacological Correction of Oxidative Stress in Rat Kidneys Does Not Facilitate Diabetic Nephropathy. International Journal of Biomedicine. 2021;11(3):296-300. doi:10.21103/Article11(3)_OA8.

\section{Abbreviations}

ATA, alpha-tocopherol acetate; CAT, catalase; DM, diabetes mellitus; DN, diabetic nephropathy; FRO, free-radical oxidation; GPx, glutathione peroxidise; OS, oxidative stress; ROS, reactive oxygen species; SOD, superoxide dismutase, TBRP, thiobarbiturate-reactive products.

\section{Introduction}

Numerous studies have proposed that OS plays a crucial role in the progression and severity of diabetic nephropathy (DN). ${ }^{(1-3)}$ The activation of FRO in the kidneys, against the background of diabetes mellitus (DM), has been shown in many works, including our previous study.(4) However, the mechanisms that develop oxidative damage to the renal glomerulus are quite diverse. They can be direct and indirect. It is generally accepted that in DM, glucose and its metabolites in urine can directly suppress the activity of cellular antioxidants, such as glutathione. ${ }^{(5-8)}$ Numerous studies have shown that in DM, there exists an accumulation of advanced glycated endproducts, ${ }^{(5,9,10)}$ increased OS, ${ }^{(11)}$ and enhanced angiotensin II levels. ${ }^{(5,12)}$ The adverse effects of most of those factors have often been linked to the generation of ROS. ${ }^{(3,13)}$ Many sources 
of ROS contribute to increased OS; however, NADPH oxidases (Nox) and their catalytic subunit are the only known enzyme family solely dedicated to producing ROS. ${ }^{(3,5,13-15)}$ Furthermore, Nox isoforms are upregulated in the presence of high glucose. The resulting ROS contribute to damage to podocytes, causing nephropathy. ${ }^{(1,16-18)}$ Considering the above, it is obvious that pharmacological correction of OS in the kidneys in DM may have a beneficial effect on the course of DN. However, the question remains unresolved: Suppressing which of the above mechanisms of intrarenal OS can be most effective in treating DN? To understand this issue, in the first stage of our study we decided to evaluate the effectiveness of correcting the direct prooxidant effect of hyperglucosuria, as one of the first mechanisms in the formation of OS in DN. For this, we chose the classical direct antioxidant ATA as a pharmacological tool.

The aim of this study was to evaluate the effect of ATA on the activity of FRO in renal tissue and renal function in rats with experimental streptozotocin (STZ)-induced DM.

\section{Materials and Methods}

Experiments were conducted on 22 male Wistar rats aged 60-100 days and weighing 250-300g. The work with animals was carried out in accordance with the principles of humanism laid down in the directives of the European Community (86/609/EEC) and the Declaration of Helsinki, in accordance with the "Animal experimentation legislations."

The animals were divided into two groups. In Group 1 (control) $(\mathrm{n}=10)$, to induce DM, the animals were injected intraperitoneally $1 \mathrm{ml}$ of STZ solution in the citrate buffer at a dose of $65 \mathrm{mg} / \mathrm{kg}$. For more selective modeling of type 2 $\mathrm{DM}$, the rats were previously injected with an intraperitoneal solution of cytoflavin based on a nicotinamide dose of $115 \mathrm{mg} /$ kg.. ${ }^{(19)}$ In Group 2 (experimental) ( $\left.\mathrm{n}=12\right)$, DM was simulated in a similar way and ATA was administered. In preliminary studies, we have shown that typical signs of nephropathy in rats, including OS in the kidneys, develop as early as 4 weeks after the administration of STZ. ${ }^{(20)}$ At the same time, we also found that in rats with 8-month DM, pathological changes in the kidneys become extremely pronounced and, most likely, irreversible. ${ }^{(21)}$ The results obtained show that the most reliable assessment of the effectiveness of pharmacological correction of DN is possible mainly in the early stages of $\mathrm{DN}$, and therefore the total duration of the experiment in this study was 8 weeks (4 weeks of STZinduced DM, then another 4 weeks - treatment). In Croup 2, ATA was administered in the period from the fifth to eighth weeks, inclusive, intragastrically through a tube at a daily dose of $300 \mathrm{mg} / \mathrm{kg}$. This dose was chosen based on the results of our previous experiments to study the effect of ATA on the course of experimental oxalate nephrolithiasis. ${ }^{(22)}$ In both groups, before starting diabetes modeling, and then weekly, we determined the concentration of glucose, protein, and creatinine in the urine, and their urinary excretion was calculated.

In urine, the concentration of glucose, protein, and creatinine was determined on the automatic biochemical analyzer DIRUICS-T240 using commercial biochemical kits
(DIAKON-DS, Russia). After 8 weeks of the experiment, the rats were euthanized under ethereal anesthesia and both kidneys were extracted, one of which was used for morphological research, and the other one was used to determine the biochemical markers of oxidative stress.

The activity of FRO in the kidneys of the rats was assessed by measuring the concentration of TBRP in the renal tissue homogenate and the activity of antioxidant enzymes (SOD, CAT, GPx). ${ }^{(15,22)}$ The morphological study was carried out according to the scheme we approved in previous experiments. ${ }^{(20)}$

Statistical analysis was performed using using a special program Statistica 13.3.1 (license JPZ906I448517FAACD-K). The normality of distribution of continuous variables was tested by one-sample Kolmogorov-Smirnov test. Continuous variables with normal distribution were presented as mean (standard error of the mean [SEM]); non-normal variables were reported as median (Me) and interquartile range (IQR; 25th to 75 th percentiles). The Mann-Whitney U Test was used to compare the differences between the two independent groups. The Wilcoxon criterion was used to compare the differences between the paired samples. A probability value of $P<0.05$ was considered statistically significant.

\section{Results}

Experiments showed that after a 4-week course of ATA, the TBRP concentration in the kidney tissues of the rats in Group 2 was 5.3 times lower than in Group 1. The activity of all antioxidant enzymes did not differ between the two groups (Table 1).

Table 1.

Indicators of activity of FRO in the kidneys of the rats

\begin{tabular}{|l|c|c|c|}
\hline \multicolumn{1}{|c|}{ Variable } & $\begin{array}{c}\text { Group 1 } \\
(\text { Control })\end{array}$ & $\begin{array}{c}\text { Group 2 } \\
\text { (Experiment) }\end{array}$ & $P$-value \\
\hline $\begin{array}{l}\text { TBRP concentration } \\
(\mu \mathrm{mol} / \mathrm{mg})\end{array}$ & $\begin{array}{c}10.1 \\
(8.3 ; 13.5)\end{array}$ & $\begin{array}{c}1.9 \\
(1.6 ; 2.3)\end{array}$ & $<0.0000$ \\
\hline CAT activity (\%) & $\begin{array}{c}9.8 \\
(6.2 ; 27.1)\end{array}$ & $\begin{array}{c}9.5 \\
(7.7 ; 24.1)\end{array}$ & $>0.05$ \\
\hline SOD activity (\%) & $\begin{array}{c}6.8 \\
(4.7 ; 8.5)\end{array}$ & $\begin{array}{c}6.5 \\
(4.8 ; 10.3)\end{array}$ & $>0.05$ \\
\hline GPx activity (\%) & $\begin{array}{c}34.7 \\
(31.4 ; 37.3)\end{array}$ & $\begin{array}{c}37.2 \\
(34.0 ; 40.0)\end{array}$ & $>0.05$ \\
\hline
\end{tabular}

In Group 1, during all 8 weeks of the experiment, the levels of renal excretion of glucose, protein, and creatinine significantly exceeded the initial level, while the level of diuresis remained stable (Table 2). In Group 2, despite the course of treatment, the described parameters did not differ from Group 1.

The results of a morphological study showed that after 8 months of STZ-induced DM, the kidney glomeruli of the Group 1 animals were enlarged. In addition, there was a significant expansion of the intercapillary space due to the accumulation of Schiff-positive mesangium and connective tissue. 
Table 2.

Indicators of excretory kidney function in the two groups

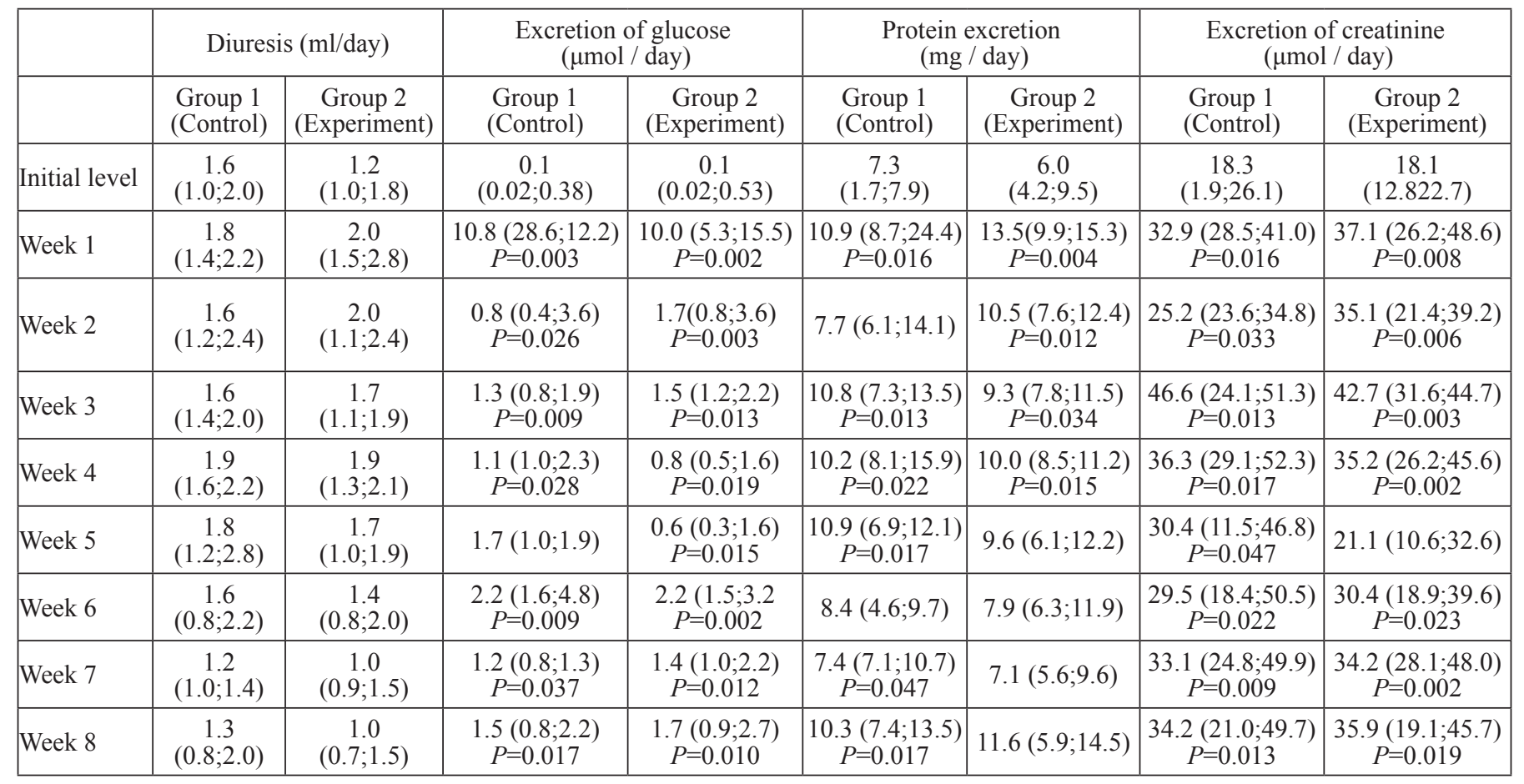

$P$-level of significance with the initial data

The basal membranes of the glomeruli capillaries were significantly thickened, the capillary lumen was narrowed. The capsule of the kidney glomeruli looked thickened. Glomeruli capillaries were full-blooded. In the kidney interstitium, there were foci of lymphoplasmacytic infiltration. The tubular lumens were expanded; the basal membranes of the tubulars were thickened. Nephrocytes were in a state of hyaline-drop dystrophy. The walls of the arteries were thickened; the elastic membranes were hyperplastic. The blood vessels were in a state of plethora (Fig 1).

In the Group 2 animals, the size of the kidney glomeruli decreased slightly, compared to Group 1; the intercapillary space was expanded due to the accumulation of Schiffpositive mesangium and connective tissue. The basal membranes of the glomeruli capillaries were thickened, the capillary lumen was narrowed. The capsule of the kidney glomeruli looked thickened. Glomeruli capillaries were fullblooded. In the kidney interstitium, there were single foci of lymphoplasmacytic infiltration. The tubular lumens were expanded; the basal membranes of the tubulars were thickened. Nephrocytes were in a state of hyaline-drop dystrophy. The walls of the vessels were moderately thickened; the elastic membranes were hyperplastic (Fig.2).

Table 3 presents the quantitative indicators of the morphometric study of the kidneys of both groups of rats. Statistically significant differences between groups were not identified.

The question of whether oxidative stress is primarily responsible for the diabetic complications was extensively investigated, but remained unanswered. The results obtained, to a certain extent, were unexpected. On the one hand,
ATA exerted its direct antioxidant effect in the kidneys, as evidenced by a fivefold decrease (relative to the control group) in the concentration of TBRP, the main marker of membrane phospholipid peroxidation. At the same time, ATA had no effect on the activity of antioxidant enzymes, which is also in good agreement with the direct non-enzymatic nature of the antioxidant effect of ATA.

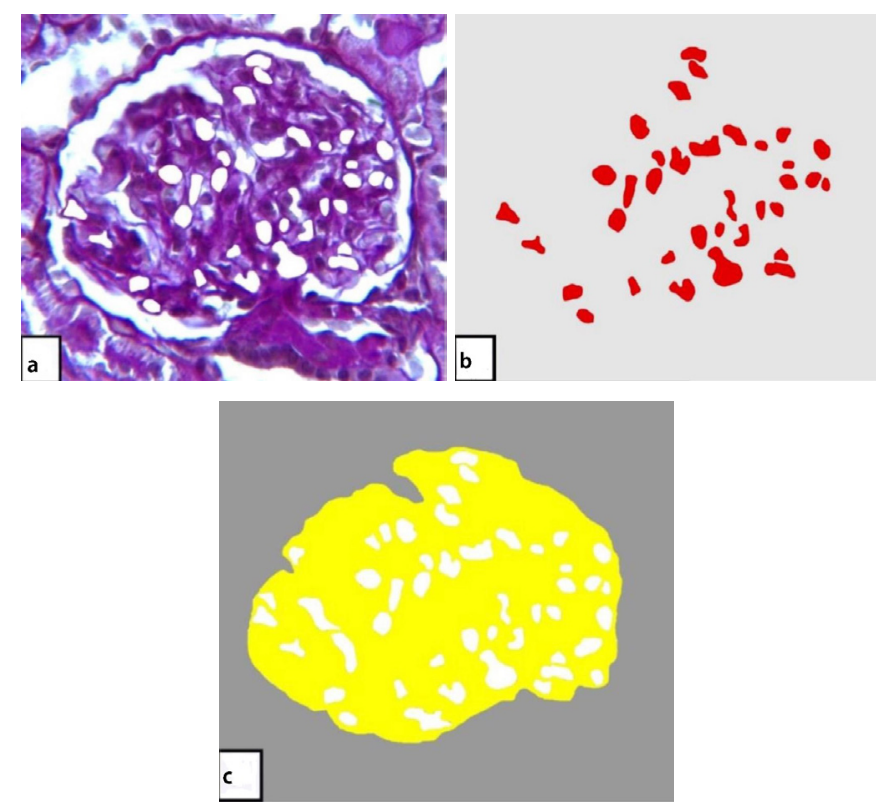

Fig. 1. Control group.

(a) - Kidney glomerulus; (b) - Luminal narrowing of capillaries; (c) - Increased mesangial area. McManus staining method; computer processing of photomicrographs $(\times 1200)$. 


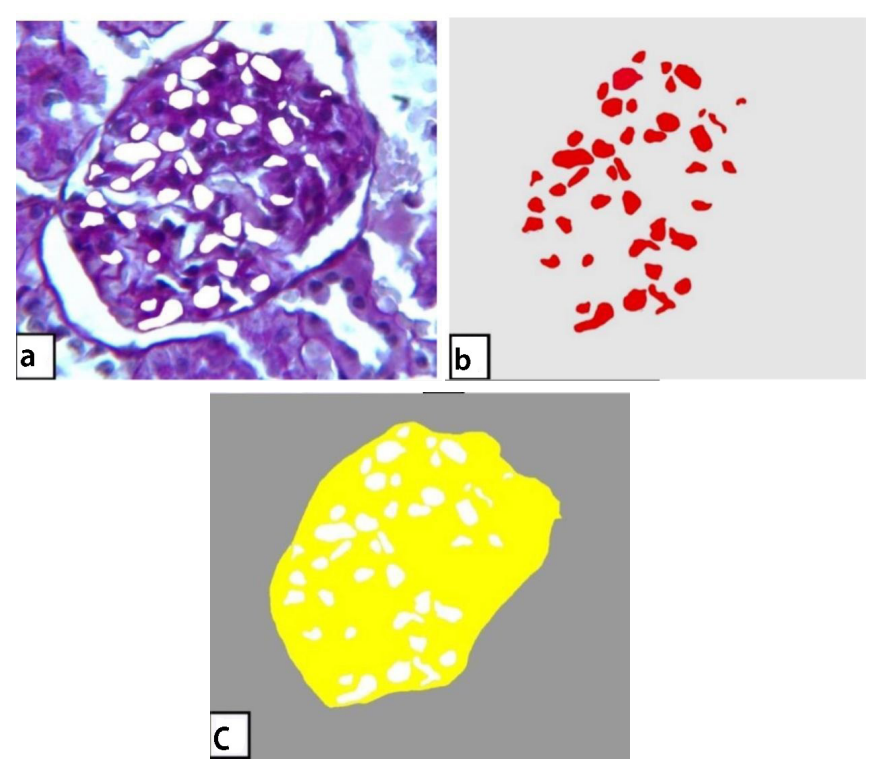

Fig. 2. Experimental group.

(a) - Kidney glomerulus; (b) - Luminal narrowing of capillaries; (c) - Increased mesangial area. McManus staining method; computer processing of photomicrographs $(\times 1200)$.

Table 3.

The quantitative indicators of the morphometric study of the kidneys of both groups of rats

\begin{tabular}{|l|c|c|c|}
\hline \multicolumn{1}{|c|}{ Indicators } & $\begin{array}{c}\text { Group 1 } \\
\text { (Control) }\end{array}$ & $\begin{array}{c}\text { Group 2 } \\
\text { (Experiment) }\end{array}$ & P-level \\
\hline $\begin{array}{l}\text { The area of the renal } \\
\text { glomeruli }\left(\mu \mathrm{m}^{2}\right)\end{array}$ & $7089.5 \pm 262.7$ & $6316.3 \pm 115.5$ & $>0.05$ \\
\hline $\begin{array}{l}\text { The total area of blood } \\
\text { vessels in the glomerulus } \\
\left(\mu \mathrm{m}^{2}\right)\end{array}$ & $1064.6 \pm 115.5$ & $953.3 \pm 112.5$ & $>0.05$ \\
\hline $\begin{array}{l}\text { Glomerular capillary } \\
\text { lumen area } \\
\left(\mu \mathrm{m}^{2}\right)\end{array}$ & $22.65 \pm 1.8$ & $23.25 \pm 2.1$ & $>0.05$ \\
\hline $\begin{array}{l}\text { Mesangium area in } \\
\text { the glomeruli }\left(\mu \mathrm{m}^{2}\right)\end{array}$ & $5396.6 \pm 85.8$ & $4548.1 \pm 115.5$ & $>0.05$ \\
\hline $\begin{array}{l}\text { The number of podocytes } \\
\text { in the glomerulus }\end{array}$ & $28.2 \pm 2.9$ & $34.3 \pm 2.3$ & $>0.05$ \\
\hline
\end{tabular}

At the same time, ATA did not cause any significant changes in the development of experimental pathology. A high level of proteinuria and glomerular filtration rate persisted, and morphological changes in tissues and cells of the renal glomeruli were identical to the control.

The results obtained suggest that the suppression of the direct component of the oxidative effect of glucose and its metabolic products is insufficient to normalize the structure and function of the renal filtration barrier. It is possible that the mediated mechanisms of oxidation make a much more significant contribution to the development of nephropathy. In this regard, the search for effective methods of pharmacological correction of DN implies further study of the effects of OS on the development of nephropathy.
It should be noted that the effect of ATA on the course of DN has been studied by various researchers. There are a number of studies showing the effectiveness of this drug as an antioxidant in the treatment of DN. ${ }^{(23-25)}$ At the same time, other authors believe that the role of ATA in the correction of $\mathrm{DN}$ is controversial and needs to be studied further. The results of our study showed that ATA, while exerting a pronounced suppression of FRO in the kidneys in experimental DM, did not contribute to the correction of DN.

In conclusion, the long-term administration of ATA in experimental streptozotocin (STZ)-induced DM is accompanied by a significant suppression of the activity of the FRO processes in the kidneys, but does not lead to an improvement in the course of DN.

\section{Competing Interests} interests.

The authors declare that they have no competing

\section{References}

1. Sagoo MK, Gnudi L. Diabetic nephropathy: Is there a role for oxidative stress? Free Radic Biol Med. 2018 Feb 20;116:50-63. doi: 10.1016/j.freeradbiomed.2017.12.040.

2. Balabolkin MI, Klebanova EM. [The role of oxidative stress in the pathogenesis of vascular complications of diabetes (lecture)]. Problems of Endocrinology. 2000;46(6):29-34 . [Article in Russian].

3. Kaneto H, Katakami N, Matsuhisa M, Matsuoka TA. Role of reactive oxygen species in the progression of type 2 diabetes and atherosclerosis. Mediators Inflamm. 2010;2010:453892. doi: $10.1155 / 2010 / 453892$.

4. Filinova SO, Zharikov AYu, Mazko ON, Makarova OG, Balandovich BA. [Indicators of pro-oxidant and antioxidant status in kidneys of rats with experimental diabetes]. Pathological Physiology and Experimental Therapy. 2020;64(1):124-127. [Article in Russian].

5. Borisenok OA, Bushma MI, Basalay ON, Radkovets AYu. [Biological Role of Glutathione]. Meditsinskie Novosti. 2019;7(298): 3-8. [Article in Russian].

6. Putt DA, Zhong Q, Lash LH. Adaptive changes in renal mitochondrial redox status in diabetic nephropathy. Toxicol Appl Pharmacol. 2012 Jan 15;258(2):188-98. doi: 10.1016/j. taap.2011.10.021.

7. Kulinsky VI, Kolesnichenko LS. [The biological role of glutathione]. Uspehi Sovremennoj Biologii. 1990;110(1):2037. [Article in Russian].

8. Kulinsky VI, Kolesnichenko LS. [Glutathione exchange]. Advances in biological chemistry. 1990;31:157-179. [Article in Russian].

9. Cohen MP, Ziyadeh FN. Role of Amadori-modified nonenzymatically glycated serum proteins in the pathogenesis of diabetic nephropathy. J Am Soc Nephrol. 1996 Feb;7(2):18390. doi: 10.1681/ASN.V72183.

*Corresponding author: Svetlana O. Filinova. Altai State Medical University, Barnaul, the Russian Federation. E-mail: filinova.87@inbox.ru 
10. Kilhovd BK, Giardino I, Torjesen PA, Birkeland KI, Berg TJ, Thornalley PJ, Brownlee M, Hanssen KF. Increased serum levels of the specific AGE-compound methylglyoxal-derived hydroimidazolone in patients with type 2 diabetes. Metabolism. 2003 Feb;52(2):163-7. doi: 10.1053/meta.2003.50035.

11. Cadenas E, Davies KJ. Mitochondrial free radical generation, oxidative stress, and aging. Free Radic Biol Med. 2000 Aug;29(3-4):222-30. doi: 10.1016/s08915849(00)00317-8.

12. Zanella MT, Ribeiro AB. The role of angiotensin II antagonism in type 2 diabetes mellitus: a review of renoprotection studies. Clin Ther. 2002 Jul;24(7):1019-34. doi: 10.1016/s0149-2918(02)80016-9.

13. Brownlee M. Biochemistry and molecular cell biology of diabetic complications. Nature. 2001 Dec 13;414(6865):81320. doi: $10.1038 / 414813 \mathrm{a}$.

14. Bhattacharjee N, Barma S, Konwar N, Dewanjee S, Manna P. Mechanistic insight of diabetic nephropathy and its pharmacotherapeutic targets: An update. Eur J Pharmacol. 2016 Nov 15;791:8-24. doi: 10.1016/j.ejphar.2016.08.022.

15. Novikov VE, Levchenkova OS, Pozhilova YV. [Role of reactive oxygen species in cell physiology and pathology and their pharmacological regulation]. Reviews on Clinical Pharmacology and Drug Therapy. 2014;12(4):13-21. [Article in Russian].

16. Gnudi L. Podocytes and the struggle against glucose toxicity: new targets for treatment? Metabolism. 2012 Aug;61(8):1051-4. doi: 10.1016/j.metabol.2012.01.015.

17. Bobkova IN, Shestakova MV, Shchukina AA. Diabetic Nephropathy - Focus on Podocytes Damage. Nephrology (Saint-Petersburg). 2015;19(2):33-44. [Article in Russian].

18. Kim NH. Podocyte hypertrophy in diabetic nephropathy.
Nephrology (Carlton). 2005 Oct;10 Suppl:S14-6. doi: 10.1111/j.1440-1797.2005.00450.x.

19. Spasov AA, Vorohkova MP, Snegur GL, Cheplyaeva NI, Chepurnova MV. Experimental Model of Type 2 Diabetes. Biomedicine 2011;(3):12-18. [Article in Russian].

20. Filinova SO, Zharikov AY, Bobrov IP, Mazko ON, Makarova OG. [Pathomorphological picture of diabetic nephropathy in experimental diabetes mellitus]. Kazan Medical Journal 2019;100(1):147-152. [Article in Russian].

21. Zharikov AYu, Filinova SO, Mazko ON, Makarova OG, Korenovsky YuV, Lepilov AV, Bobrov IP, Azarova OV. Comparison of the Pathological Picture of Experimental Diabetic Nephropathy in Rats at Early (1 month) and Late (8 months) Stages. International Journal of Biomedicine. 2019;9(4):345-349. doi: 10.21103/Article9(4) OA14

22. Zharikov AYu, Talalaeva OS, Zverev YaF, Lampatov VV, Azarova OV, Kudinov AV, Motin YuG. [The role of antioxidant therapy in experimental pharmacological correction of nephrolithiasis]. Nephrology (Saint-Petersburg). 2010;14(4):53-58. [Article in Russian].

23. Hayashi D, Ueda S, Yamanoue M, Ashida H, Shirai Y. Amelioration of diabetic nephropathy by oral administration of $\mathrm{d}$ - $\alpha$-tocopherol and its mechanisms. Biosci Biotechnol Biochem. 2018 Jan;82(1):65-73. doi: 10.1080/09168451.2017.1411184.

24. Bondar' IA, Klimentov VV. Antioxidants in the treatment and prevention of diabetes mellitus. Diabetes mellitus. 2001;4(1):47-52. [Article in Russian].

25. Kuznetsov NS, Abulela AM, Neskoromny VN. Antioxidants (alpha-Tocopherol acetate) in the therapy of diabetes mellitus. Problems of Endocrinology. 1993;39(2):911. [Article in Russian]. 